\title{
Adverse metabolic phenotype in low-birth-weight lambs and its modification by postnatal nutrition
}

\author{
Jacqueline M. Wallace*, John S. Milne, Clare L. Adam and Raymond P. Aitken \\ Rowett Institute of Nutrition and Health, University of Aberdeen, Bucksburn, Aberdeen AB21 9SB, UK
}

(Received 13 January 2011 - Revised 4 April 2011 - Accepted 9 May 2011 - First published online 5 July 2011)

\begin{abstract}
Both high and low maternal dietary intakes adversely affect fetal nutrient supply in adolescent sheep pregnancies. Aims were: (a) to assess the impact of prenatal nutrition on pregnancy outcome, offspring growth and offspring glucose metabolism and (b) to determine whether the offspring metabolic phenotype could then be altered by modifying postnatal nutrition. Dams carrying a single fetus were offered either an optimal control (C) intake to maintain adiposity throughout pregnancy, undernourished to maintain weight at conception but deplete maternal reserves (UN), or overnourished to promote rapid maternal growth and adiposity (ON). Placental weight and gestation length were reduced in $\mathrm{ON}$ dams and lamb birth weights were $\mathrm{C}>\mathrm{UN}>\mathrm{ON}(P<0 \cdot 001)$. All offspring were fed ad libitum from weaning to 6 months of age. ON offspring exhibited rapid catch-up growth and had increased fasting glucose and relative glucose intolerance compared with $\mathrm{C}$ offspring $(P<0 \cdot 05)$. Irrespective of prenatal diet and sex, birth weight correlated negatively with these indices of glucose metabolism. From 7 to 12 months offspring either had continued ad libitum diet (ADLIB; to induce an obesogenic state) or a decreased ration appropriate for normal growth (NORM). At 12 months, the negative relationship between birth weight and indices of glucose metabolism persisted in ADLIB females (for example, fasting glucose, $r-0.632 ; P<0.03$ ) but was absent in NORM females and in both male groups. Therefore, low-birth-weight offspring from differentially achieved prenatal malnutrition exhibit an early adverse metabolic phenotype, and this can apparently be ameliorated by postnatal nutrition in females but not in males.
\end{abstract}

Key words: Maternal nutrition: Intra-uterine growth restriction: Fetal programming: Glucose intolerance: Metabolic syndrome

Human epidemiological studies have linked presumed fetal malnutrition leading to low birth weight with the subsequent development of the metabolic syndrome and CVD in later life $\mathrm{e}^{(1-3)}$. Compelling evidence that a poor maternal diet during pregnancy is the root cause comes from studies of adults whose mothers were pregnant during the Dutch famine at the end of the Second World War. Male and female offspring of women exposed to famine during mid and late pregnancy had lower birth weights and reduced glucose tolerance at age 50 years whilst exposure during early pregnancy was associated with increased risk of CHD and an atherogenic lipid profile in both sexes, and increased central obesity in females ${ }^{(4-7)}$. A number of large animal models have investigated the relationships between maternal nutrition, birth weight and the emergence of the risk factors associated with the metabolic syndrome (i.e. impaired glucose homeostasis, hypertension, central obesity, dyslipidaemia and elevated inflammatory indices) with the primary focus being the impact of maternal undernutrition. The sheep is the species of choice for these studies because of similarities with man in respect of maternal size and adiposity, and fetal size, organ development, physiology and maturity at birth $^{(8,9)}$. Thus, low maternal adiposity at conception ${ }^{(10)}$ and maternal nutrient restriction during the periconception ${ }^{(11)}$, early to mid pregnancy ${ }^{(12)}$ and late pregnancy periods ${ }^{(13)}$ have all been associated with impaired glucose tolerance in young adult life (assessed between 8 and 16 months). However, birth weight was not perturbed in any of these studies and while the programming of postnatal metabolic function without significant changes in size at birth is of interest, it does not mirror the human epidemiological relationships referenced above and now established for populations around the globe. Thus the primary aim of the present study was to examine glucose tolerance in male and female lambs whose prenatal growth trajectories have been impaired by contrasting maternal dietary intake levels during pregnancy, leading ultimately to low birth weight.

Abbreviations: ADLIB, ad libitum diet; AUC, area under the curve; C, control; FGR, fractional growth rate; glucose AUC, area under the glucose response curve; insulin AUC, area under the insulin response curve; NORM, decreased ration appropriate for normal growth diet; ON, overnourished; UN, undernourised.

*Corresponding author: Dr Jacqueline Wallace, fax + 441224 716686, email Jacqueline.Wallace@abdn.ac.uk 
Two contrasting models of nutritionally mediated prenatal growth restriction were utilised. Both employed assisted conception procedures to limit pregnancies to a single fetus and to maximise offspring genetic homogeneity. These models variously reproduce the adverse pregnancy outcomes associated with young human adolescent pregnancies but additionally have wider relevance to human intra-uterine growth restriction independent of maternal age ${ }^{(14,15)}$. In the overnourished adolescent sheep model, rapid maternal growth and adiposity are promoted at the expense of conceptus nutrient requirements and major reductions in placental mass, uteroplacental blood flows, and hence fetal nutrient supply, are evident by the final third of gestation ${ }^{(16,17)}$. In late pregnancy relative to normally growing controls, the fetuses from overnourished dams are asymmetrically growth restricted, hypoxic, hypoglycaemic and hypoinsulinaemic ${ }^{(17,18)}$ but have higher body weight-specific perirenal fat mass and carcass fat content ${ }^{(19)}$ and normal body weight-specific metabolic responses to short-term increases in insulin and/or glucose ${ }^{(20)}$. Spontaneous delivery occurs on average $3 \mathrm{~d}$ early and lambs are typically $30 \%$ lighter at birth. Thus the offspring of overnourished dams are classified as growth-restricted primarily due to small placental size, with a characteristic fat phenotype at birth. By contrast, in the undernourished model, adolescent ewes are fed sufficient food only to maintain maternal body weight at conception levels. This prevents further maternal body growth during pregnancy and progressively depletes maternal body reserves relative to controls. Nutrient availability in the maternal circulation is decreased and there is a modest but significant slowing of fetal soft tissue growth from mid to late pregnancy, which, in contrast to the overnourished adolescent paradigm, is independent of placental growth $^{(21,22)}$. By late pregnancy the fetuses of these undernourished dams are also mildly hypoglycaemic and have lower body weight-specific perirenal fat mass commensurate with a thin phenotype at birth.

Postnatal growth patterns also potentially influence metabolic health, and studies in human subjects ${ }^{(23-26)}$, rodents $^{(27,28)}$ sheep $^{(29)}$ and pigs ${ }^{(30,31)}$ demonstrate that major prenatal growth restriction followed by birth into an adequate or nutrient-rich environment results in rapid catch-up growth and adverse metabolic phenotypes (for example, impaired glucose tolerance, insulin resistance, hypertension and/or obesity) in later life. In the majority of these studies the impact of low birth weight $v$. rapid catch-up growth has not been assessed separately and, where they have, few independent effects of the early postnatal growth pattern have been established ${ }^{(29,32)}$. Nevertheless directly limiting nutrient exposure during the immediate postnatal period to prevent catch-up growth prevents the development of glucose intolerance and obesity in a mouse model of low birth weight-associated diabetes, suggesting that prenatal metabolic adaptations to a poor nutrient supply are not permanent ${ }^{(33)}$. Thus the secondary aim of the present study was to determine whether the predicted relationship between size at birth and glucose intolerance in lambs with ad libitum postnatal access to a nutrient-dense diet could be ameliorated by imposing a period of relative nutrient restriction between adolescent and young adult life.
Thus the purpose herein was to assess the impact of wide variations in maternal dietary intake during gestation on pregnancy outcome, offspring growth and offspring glucose metabolism and to determine whether the offspring metabolic phenotype could then be altered by modifying postnatal nutrition.

\section{Materials and methods}

\section{Establishment of pregnancy}

All procedures were licensed under the UK Animals (Scientific Procedures) Act of 1986 and approved by the Rowett Institute of Nutrition and Health's Ethical Review Committee.

Embryos from superovulated adult ewes (Border Leicester $X$ Scottish Blackface), inseminated by a single sire, were recovered on day 4 after oestrus and transferred synchronously in singleton into the uterus of recipient ewe lambs (Dorset Horn $\times$ Greyface), as described previously ${ }^{(34)}$. This approach removes the potentially confounding influence of partial embryo loss and variation in fetal number and maximises the homogeneity of the resulting fetuses. Donor ewes were multiparous, between 3 and 4 years of age, had a body weight of 72 (SEM 1.4) $\mathrm{kg}$ and an adiposity score of 2.5 (SEM 0.05) units (based on a five-point scale, where $1=$ emaciated and $5=$ morbidly obese; Russel et al. $\left.{ }^{(35)}\right)$. Embryo transfers were carried out on six separate days during the mid-breeding season. Recipient ewes ( $n$ 74) were peripubertal (about 8 months of age) and had a mean live weight of 46.4 (sEm $0 \cdot 27$ ) $\mathrm{kg}$ and adiposity score of $2 \cdot 3$ (SEM 0.01) units at the time of embryo transfer. All recipients were housed in individual pens under natural lighting conditions throughout pregnancy and lactation.

\section{Experimental design}

Maternal dietary treatments during pregnancy. On the day of embryo transfer, recipients were evenly allocated to one of three nutritional treatment groups (control, overnourished and undernourished) on the basis of weight, adiposity and ovulation rate at the time of embryo transfer. Care was also taken to randomise for embryo donor within each embryo transfer day. Following a $3 \mathrm{~d}$ post-surgery re-alimentation period, these groups were offered varying levels of the same complete diet from day 7 post-ovulation (equivalent to day 7 of pregnancy). This diet supplied $12 \mathrm{MJ}$ metabolisable energy and $140 \mathrm{~g}$ crude protein per $\mathrm{kg}$ and was offered in two equal feedings at 08.00 and 16.00 hours daily (see Wallace et $a l{ }^{(36)}$, for full details of the diet composition and analyses). The dietary level offered in the control group (C) was calculated to maintain normal maternal adiposity throughout gestation (i.e. no change from initial starting adiposity) and hence meet the estimated metabolisable energy requirements for optimum conceptus growth and pregnancy outcome in this genotype. To achieve this objective, group $\mathrm{C}$ was fed to promote a modest maternal weight gain target of about $50 \mathrm{~g}$ per d during the first two-thirds of gestation, followed by stepwise increases in maternal intake during the final third 
of gestation, calculated to meet the increasing demands of the developing fetus. The high dietary level offered in the overnourished group (ON) was designed to promote rapid gestational weight gain and increasing maternal adiposity throughout gestation. The level of feed offered was increased gradually over a 2 -week period until the level of the daily feed refusal was about $15 \%$ of the total offered (equivalent to ad libitum intakes). In the undernourished group (UN), the dietary level was designed to maintain maternal body weight at conception values but was nonetheless predicted to deplete maternal tissue reserves throughout gestation. In practical terms we have previously established that this is approximately $0.75 \times$ control group intakes during the first two-thirds of gestation $^{(21)}$ with no further stepwise increase in intake during the final third of gestation. Individual adiposity scores in undernourished dams were not allowed to fall below 1.5 score units to comply with the terms of the authorising project license approved by the UK Home Office. Throughout pregnancy individual levels of feed offered were reviewed three times weekly and adjusted as required on the basis of daily feed refusal rates and approximately twice weekly body-weight-change data and fortnightly assessment of adiposity score.

Pregnancy and parturition management and measurements. Conception rate was determined by transabdominal ultrasonography at day 45 of gestation (gestation length $=145 \mathrm{~d}$ ). Pregnancy outcome was determined after spontaneous delivery at term. All ewes were supervised throughout the delivery period. Lambs were dried and weighed after delivery. Lamb girth at the umbilicus was measured and the sex recorded. Lamb height at the shoulder was measured at about $12 \mathrm{~h}$ after birth. Ewe colostrum yield was measured before lamb suckling and within $30 \mathrm{~min}$ of parturition. After intravenous injection of oxytocin (10 i.u. per ewe; Oxytocin- ${ }^{\circledR}$; Intervet Ltd, Cambridge, Cambs, UK), ewes were milked by hand until all the colostrum had been removed from the udder. The colostrum was weighed, sampled for IgG and nutrient composition analyses carried out as described previously ${ }^{(36)}$ and then fed to the ewe's own lamb by bottle at a rate of $50 \mathrm{ml} / \mathrm{kg}$ body weight. In cases where the dam had insufficient colostrum, frozen ewe colostrum (matched for gestational intake group) was substituted to ensure lamb survival. Lambs were weighed at 4 hourly intervals throughout the first $72 \mathrm{~h}$ of life. Any lamb that failed to suckle or gain in weight over an $8 \mathrm{~h}$ period was offered supplementary colostrum (first $24 \mathrm{~h}$ ) or ewe milk until the ewe-lamb bond and appropriate lactation was established (by $72 \mathrm{~h}$ after birth in all cases). The frequency of these supplementary feeds per lamb was recorded. After the placenta (fetal cotyledons and membranes) was delivered, it was weighed and cotyledons dissected, counted and weighed. At the end of the early neonatal period (i.e. $72 \mathrm{~h}$ after birth), fifty-three viable offspring were available for further study (representing about $72 \%$ survival of the transferred embryos in each group), with sixteen (eight male and eight female), sixteen (ten male and six female) and twenty-one (eleven male and ten female) lambs from the $\mathrm{C}, \mathrm{ON}$ and UN groups, respectively.
Lactation management and measurements. Following parturition all ewes were offered the complete diet to appetite to maximise milk availability. For the previously UN and $\mathrm{C}$ dams this was achieved stepwise over a period of approximately $10 \mathrm{~d}$. Lamb offspring had access to their mothers' feed during lactation and were weaned at 11 weeks of age.

Post-weaning nutritional management of offspring. Thereafter all offspring remained in the individual pens in which they were born and were fed the same complete diet as described above ad libitum until a glucose tolerance test was carried out at 6 months of age (see below). Then offspring of each sex were allocated evenly as far as possible into two groups based on maternal diet prenatally, birth weight and fractional growth rate (FGR) to 6 months of age. Subsequently, between 7 and 12 months of age, one group continued to receive the complete diet ad libitum to promote an enhanced obesogenic state (ADLIB), while the second group received a normal or control ration calculated to promote a slow growth rate and normal adiposity for age/stage of maturity (NORM). The glucose tolerance test was then repeated at 12 months of age. Offspring were weighed weekly throughout lactation and both weight and external adiposity score were assessed regularly thereafter. All offspring remained gonad intact throughout.

Offspring blood sampling, metabolic challenges and biochemical analyses. Offspring were blood sampled at birth, days 1, 3 and 7 and weekly thereafter throughout the 11-week lactation to determine plasma lipid profile. At 6 and 12 months of age a glucose tolerance test was performed to determine glucose handling. On the day before these metabolic tests offspring were fed as normal in the morning and then offered a standard ration equivalent to about $25 \%$ of average daily intake for the preceding week at 15.00 hours. Any residual food was removed $1 \mathrm{~h}$ later and offspring were fasted until the challenge had been completed the following afternoon. Offspring had free access to water throughout. Two temporary jugular catheters (one for infusion and one for sampling) were inserted at 07.00 hours the following morning. At $3 \mathrm{~h}$ later basal glucose and insulin concentrations were determined in three fasting blood samples $(-30,-15$ and $0 \mathrm{~min}$ ). Glucose handling was assessed following intravenous glucose $(0.5 \mathrm{~g} / \mathrm{kg}$ body weight, infused over $2 \mathrm{~min}$; TPS Medical, Glasgow, UK) at time 0. Blood samples were subsequently collected at $+5,10,15,20,30,45,60,90,120$ and $180 \mathrm{~min}$ into chilled heparinised tubes. Plasma was separated by centrifugation at $1000 \mathrm{~g}$ for $20 \mathrm{~min}$ and stored at $-20^{\circ} \mathrm{C}$ until assayed for insulin, glucose, lipids and NEFA as appropriate.

Insulin concentrations were measured in duplicate (after appropriate dilution with assay buffer where required) by RIA as described previously ${ }^{(37)}$. The limit of detection was $0 \cdot 15 \mu \mathrm{g}$ insulin/ $\mathrm{ml}$ and the inter- and intra-assay $\mathrm{CV}$ were 7.2 and $4.5 \%$. Plasma lipid and NEFA concentrations were determined using an automated clinical analyser (KONE) using kits supplied by the manufacturer (Labmedics, Manchester, UK); variation between duplicates was $<5 \%$ in all cases. Plasma glucose concentrations were measured in duplicate with a dual biochemistry analyser (model 2700; Yellow Springs Instruments; Yellow Springs, $\mathrm{OH}$, USA). The instrument was 
calibrated with known standards after every fourth determination and variation between duplicates was $<2 \%$.

Data analyses. Data are presented as mean values with their standard errors and all statistical comparisons were made using Minitab (version 15; Minitab Inc., State College, PA, USA). Maternal gestational weight and adiposity changes and pregnancy outcome parameters (i.e. gestation length, placental weight, lamb birth weight, colostrum yield and composition) in relation to prenatal nutritional treatment were analysed by one-way ANOVA and then calculation of the least significant difference between individual parameter treatment means. A similar approach was used to analyse offspring lipid profiles to weaning as no sex effects were detected (see below). Offspring growth and metabolic responses at 6 months of age were analysed using the general linear model (GLM) to determine the effects of prenatal diet and sex and their interaction. Where significant effects were detected, individual combinations were subsequently compared by Tukey's method with confidence limits set at 5\%. Following the postnatal dietary manipulation between 7 and 12 months, changes in offspring weight and adiposity, and metabolic responses at 12 months of age were similarly analysed using the GLM to determine the effects of prenatal diet, postnatal diet, sex and their various interactions. With one exception (see Table 7) no significant effects of prenatal diet persisted to 12 months so only postnatal diet and sex effects are presented (see Table 6). Correlation coefficient analysis was by Pearson's product moment test where appropriate.

For the glucose tolerance test (GTT), the area under the glucose, insulin and NEFA response curves (area under the curve; AUC) was calculated (integrated plasma concentrations following glucose administration ( 5 to $180 \mathrm{~min}$ ) above the mean pre-GTT ( -30 to $0 \mathrm{~min}$ ) concentrations).

\section{Results}

\section{Pregnancy and parturition}

Maternal weight gain and adiposity changes in relation to pregnancy outcome. The serial changes in maternal weight and adiposity in response to the contrasting dietary intakes are shown in Fig. 1 and the overall changes in maternal anthropometry in relation to key pregnancy outcome parameters are detailed in Table 1 . Initial adiposity was maintained in optimally nourished $\mathrm{C}$ dams throughout gestation as per study design. In contrast, overfeeding to promote rapid gains in weight and adiposity throughout pregnancy was associated with a marked reduction in gestation length, placental growth, lamb birth weight and height relative to both $\mathrm{C}$ and UN groups. Lamb girth in offspring of ON dams was reduced relative to the $\mathrm{C}$ group only. UN adolescent dams prevented further maternal body weight gain (as detailed in Fig. 1 and confirmed by weighing the dams $24 \mathrm{~h}$ after parturition, Table 1) and depleted maternal adiposity during the second two-thirds of gestation as per the study design. This did not make an impact on gestation length or placental weight at term but did result in low birth weight compared with $\mathrm{C}$ $(P<0 \cdot 01)$, but which was not as low as the ON group
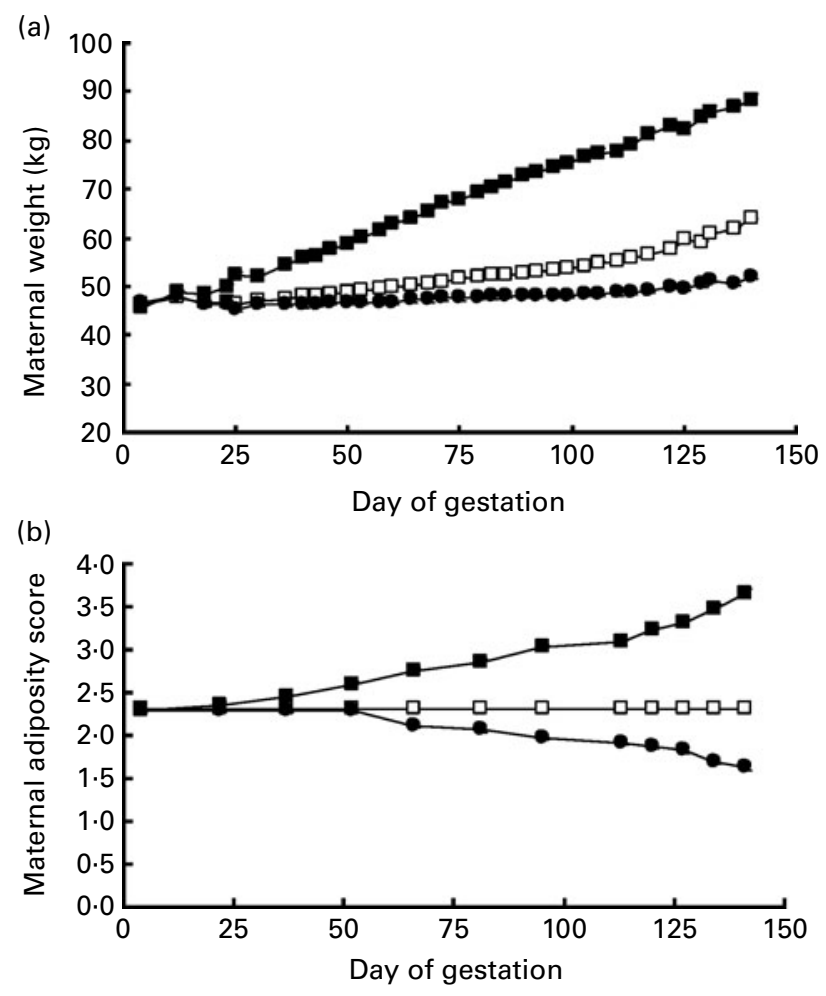

Fig. 1. Changes in maternal live weight (a) and external adiposity score (b) throughout gestation in optimally nourished control $(\square)$, overnourished ( $\square$ ) and undernourished $(\bullet)$ singleton-bearing adolescent dams (for a detailed description of the dietary manipulations, see Materials and methods). Values are means, with standard errors represented by vertical bars. Weight and adiposity of the overnourished dams first diverged $(P<0.005)$ from control group values by days 23 and 37 of gestation, respectively, while the weight and adiposity of undernourished dams first diverged $(P<0.005)$ from the control group by days 40 and 66 of gestation, respectively.

$(P<0 \cdot 001)$. These differences in birth weight between groups remained significant when the individual birth weights were adjusted to a standard gestation length of $147 \mathrm{~d}$.

Colostrum yield, IgG content and nutrient composition. Mean colostrum yield immediately after parturition was significantly suppressed in both ON and UN groups relative to the optimally nourished C group (Table 2 ). Colostrum production therefore failed to meet the initial minimum requirement of $50 \mathrm{ml} / \mathrm{kg}$ birth weight for two of sixteen, nine of sixteen and six of twenty-one neonates in the $\mathrm{C}$, ON and UN groups, respectively, and thus significantly more lambs $(P<0.05)$ born to ON mothers would not have survived without supplementation. Colostrum from both ON and UN dams had a higher IgG concentration but when adjusted for yield the total IgG available at parturition was lower $(P<0 \cdot 01)$ in the ON group only relative to the $\mathrm{C}$ group. With respect to nutrient composition, total lactose and total crude protein were reduced $(P<0.005$ or less $)$ in both the ON and UN groups relative to the controls. Colostrum fat concentration was highest in the UN group but when adjusted for yield, total colostrum fat was $\mathrm{C}>\mathrm{UN}>\mathrm{ON}$ groups. Similarly, the total energy content of the colostrum available at parturition in the $\mathrm{C}$ group was approximately three-fold higher than in the ON group $(P<0.001)$ and two-fold higher than in the UN 
Table 1. Changes in maternal weight and adiposity score, and pregnancy outcome in adolescent ewes in relation to gestational dietary intake (Mean values with their standard errors)

\begin{tabular}{|c|c|c|c|c|c|c|c|c|c|}
\hline & \multicolumn{6}{|c|}{ Gestational intake } & & & \\
\hline & \multicolumn{2}{|c|}{$\mathrm{C}(n 16)$} & \multicolumn{2}{|c|}{ ON $(n 16)$} & \multicolumn{2}{|c|}{ UN (n 21) } & \multicolumn{3}{|c|}{$P$} \\
\hline & Mean & SEM & Mean & SEM & Mean & SEM & C v. ON & C v. UN & ON v. UN \\
\hline Body-weight change, day 4 to term $(\mathrm{kg})^{\star}$ & $8 \cdot 5$ & 0.62 & 33.9 & $1 \cdot 20$ & -0.7 & 0.53 & $<0.0001$ & $<0.0001$ & $<0.0001$ \\
\hline Adiposity score change, day 4 to term & 0.02 & 0.02 & 1.3 & 0.09 & -0.7 & 0.04 & $<0.0001$ & $<0.0001$ & $<0.0001$ \\
\hline Gestation length (d) & $147 \cdot 2$ & 0.36 & $142 \cdot 7$ & 0.36 & 147.4 & 0.34 & $<0.0001$ & NS & $<0.0001$ \\
\hline Fetal placental weight (g) & 499 & $27 \cdot 2$ & 349 & $13 \cdot 1$ & 462 & $17 \cdot 0$ & $<0.0001$ & NS & $<0.0005$ \\
\hline Fetal cotyledon weight $(\mathrm{g})$ & 167 & $10 \cdot 3$ & 92 & $3 \cdot 27$ & 155 & 8.6 & $<0.0001$ & NS & $<0.0001$ \\
\hline Lamb birth weight (g) & 5558 & 136 & 4372 & 132 & 5040 & 114 & $<0.0001$ & $<0.01$ & $<0.001$ \\
\hline Adjusted birth weight $(\mathrm{g}) \dagger$ & 5535 & 125 & 4621 & 143 & 5009 & 100 & $<0.0001$ & $<0.005$ & $<0.05$ \\
\hline Birth weight:cotyledon weight & 34.5 & 1.59 & 48.5 & $2 \cdot 12$ & 34.0 & 1.62 & $<0.0001$ & NS & $<0.0001$ \\
\hline Lamb girth at umbilicus (cm) & $40 \cdot 2$ & 0.68 & $38 \cdot 2$ & 0.55 & $39 \cdot 1$ & 0.45 & $<0.05$ & NS & NS \\
\hline Lamb height at shoulder $(\mathrm{cm})$ & $38 \cdot 3$ & 0.49 & $35 \cdot 2$ & 0.58 & 37.9 & 0.41 & $<0.0005$ & NS & $<0.0005$ \\
\hline Lamb weight/height $^{2}$ & 3.80 & $0 \cdot 10$ & 3.52 & 0.09 & 3.52 & 0.07 & $<0.05$ & $<0.05$ & NS \\
\hline
\end{tabular}

C, control; ON, overnourished; UN, undernourished.

* Maternal weight at term recorded $24 \mathrm{~h}$ after parturition.

†Adjusted to average control gestation length, namely, $147 \mathrm{~d}$ as detailed previously by Wallace et al. ${ }^{\left({ }^{53}\right)}$.

group $(P<0 \cdot 005)$. There was no difference between the groups in the number of lambs (about 10\%) requiring additional supplementary colostrum or milk during the first $72 \mathrm{~h}$ of life or on the frequency of such feeds (data not shown).

\section{Offspring data}

Offspring lipid status to weaning and at 6 months of age. Plasma lipid profile at birth and averaged over the 11-week suckling period is detailed in Table 3. At birth, offspring born to ON dams had elevated plasma cholesterol and LDL concentrations relative to both the $\mathrm{C}$ and UN groups. During the suckling period, cholesterol was lowest in the UN offspring, while LDL-cholesterol was $\mathrm{ON}>\mathrm{C}>\mathrm{UN}$ offspring. Plasma concentrations of HDL and TAG were independent of maternal prenatal diet throughout. TAG concentrations and weight at birth were positively correlated in offspring of $\mathrm{C}(r 0.710 ; n 16 ; P<0.002)$ and UN $(r 0.592 ; n 21 ; P<0.005)$ but not ON dams $(P>0 \cdot 1)$. At 6 months of age the lipid profile measured in the fasting blood samples collected before metabolic challenge was independent of prenatal diet (data not shown).

Offspring growth rates and adiposity to 6 months of age. Daily live-weight gain from birth to weaning was independent of maternal prenatal diet and sex (data not shown). Thereafter, irrespective of prenatal diet, males grew faster than females and consequently were heavier at 6 months of age (Table 4; $P<0 \cdot 01)$. Absolute weight gain from birth to 6 months was independent of prenatal diet. However, when changes in absolute live weight (measured weekly) are expressed in terms of FGR (absolute weight relative to birth weight; Fig. 2) it is clear that FGR was increased in both male and female offspring of previously $\mathrm{ON}$ dams relative to both the UN and $\mathrm{C}$ groups throughout the first 6 months of postnatal life. This compensatory growth was slightly more pronounced during the birth to weaning period (see Fig. 2) and the differential in FGR between the ON compared with the UN and $\mathrm{C}$ groups was greater in male than in female offspring throughout the first 6 months of postnatal life. Irrespective of prenatal diet there was a strong negative association

Table 2. Colostrum yield, IgG content and nutrient composition in relation to gestational dietary intake (Mean values with their standard errors)

\begin{tabular}{|c|c|c|c|c|c|c|c|c|c|}
\hline & \multicolumn{6}{|c|}{ Gestational intake } & & & \\
\hline & \multicolumn{2}{|c|}{$C(n 16)$} & \multicolumn{2}{|c|}{ ON $(n 16)$} & \multicolumn{2}{|c|}{ UN ( $n$ 21) } & \multicolumn{3}{|c|}{$P$} \\
\hline & Mean & SEM & Mean & SEM & Mean & SEM & C v. ON & C v. UN & ON v. UN \\
\hline Colostrum yield (g) & 748 & 175 & 230 & 39 & 334 & 42 & $<0.001$ & $<0.005$ & NS \\
\hline \multicolumn{10}{|l|}{ Colostrum composition } \\
\hline IgG concentration $(\mathrm{mg} / \mathrm{ml})$ & $64 \cdot 7$ & 7.40 & 93.3 & $5 \cdot 22$ & 86.5 & $5 \cdot 62$ & $<0.005$ & $<0.05$ & NS \\
\hline Total IgG (g) & $36 \cdot 4$ & 4.69 & $19 \cdot 9$ & $2 \cdot 83$ & $27 \cdot 0$ & 3.51 & $<0.01$ & NS & NS \\
\hline Fat $(\mathrm{g} / 100 \mathrm{~g})$ & $13 \cdot 0$ & $1 \cdot 24$ & $10 \cdot 7$ & 0.95 & $16 \cdot 0$ & 1.07 & NS & NS & $<0.005$ \\
\hline Total fat $(\mathrm{g})$ & $81 \cdot 2$ & 13.08 & $22 \cdot 9$ & 3.42 & $49 \cdot 0$ & $6 \cdot 11$ & $<0.0001$ & $<0.01$ & $<0.05$ \\
\hline Lactose $(\mathrm{g} / 100 \mathrm{~g})$ & $3 \cdot 0$ & 0.17 & $3 \cdot 0$ & 0.17 & $2 \cdot 4$ & 0.12 & NS & $<0.01$ & $<0.01$ \\
\hline Total lactose $(\mathrm{g})$ & $23 \cdot 1$ & $5 \cdot 37$ & $6 \cdot 6$ & $1 \cdot 13$ & $8 \cdot 3$ & $1 \cdot 15$ & $<0.001$ & $<0.001$ & NS \\
\hline Crude protein $(\mathrm{g} / 100 \mathrm{~g})$ & $18 \cdot 0$ & 1.02 & $20 \cdot 9$ & 1.23 & $20 \cdot 4$ & 0.44 & NS & NS & NS \\
\hline Total crude protein $(\mathrm{g})$ & $117 \cdot 0$ & $19 \cdot 8$ & $45 \cdot 2$ & 7.54 & $65 \cdot 3$ & $7 \cdot 36$ & $<0.0005$ & $<0.005$ & NS \\
\hline Total energy content $(\mathrm{kJ})$ & 1917 & 425 & 583 & 96 & 898 & 109 & $<0.001$ & $<0.005$ & NS \\
\hline
\end{tabular}

C, control; ON, overnourished; UN, undernourished. 
Table 3. Offspring plasma lipids at birth and averaged over the 11-week suckling period in relation to gestational dietary intake (Mean values with their standard errors)

\begin{tabular}{|c|c|c|c|c|c|c|c|c|c|}
\hline & \multicolumn{6}{|c|}{ Gestational intake } & & & \\
\hline & \multicolumn{2}{|c|}{$\mathrm{C}(n 16)$} & \multicolumn{2}{|c|}{ ON $(n 16)$} & \multicolumn{2}{|c|}{ UN (n 21) } & \multicolumn{3}{|c|}{$P$} \\
\hline & Mean & SEM & Mean & SEM & Mean & SEM & C v. ON & C v. UN & ON v. UN \\
\hline \multicolumn{10}{|l|}{ Birth } \\
\hline Cholesterol (mmol/l) & 0.614 & 0.040 & 0.753 & 0.059 & 0.573 & 0.030 & $<0.05$ & NS & $<0.005$ \\
\hline LDL (mmol/l) & 0.185 & 0.023 & 0.305 & 0.036 & 0.141 & 0.018 & $<0.005$ & NS & $<0.001$ \\
\hline $\mathrm{HDL}(\mathrm{mmol} / \mathrm{l})$ & 0.450 & 0.025 & 0.456 & 0.030 & 0.444 & 0.021 & NS & NS & NS \\
\hline TAG (mmol/l) & 0.240 & 0.036 & 0.386 & 0.062 & 0.286 & 0.052 & NS & NS & NS \\
\hline \multicolumn{10}{|l|}{ Suckling period ${ }^{*}$} \\
\hline Cholesterol (mmol/l) & $2 \cdot 890$ & 0.112 & $3 \cdot 197$ & 0.191 & 2.538 & 0.065 & NS & $<0.05$ & $<0.001$ \\
\hline LDL (mmol/l) & 0.943 & 0.061 & $1 \cdot 109$ & 0.086 & 0.785 & 0.026 & $<0.08$ & $<0.06$ & $<0.001$ \\
\hline $\mathrm{HDL}(\mathrm{mmol} / \mathrm{l})$ & $1 \cdot 840$ & 0.064 & 1.984 & 0.113 & 1.667 & 0.041 & NS & NS & NS \\
\hline TAG (mmol/l) & 0.518 & 0.021 & 0.574 & 0.024 & 0.545 & 0.016 & NS & NS & NS \\
\hline
\end{tabular}

C, control; ON, overnourished; UN, undernourished.

${ }^{*}$ Average of fourteen individual values per animal from day 1 to 76 of the 11 -week suckling period.

between birth weight and FGR to 6 months of age in both male $(r-0.850 ; n 29 ; P<0.001)$ and female $(r-0.889 ; n 24$; $P<0.001)$ offspring. External adiposity score at 6 months of age was independent of prenatal diet and sex (2.5 (sem 0.03 ), 2.3 (SEM 0.05 ) and 2.4 (SEM 0.04) units in males and $2 \cdot 4$ (SEM 0.04), $2 \cdot 3$ (SEM 0.04) and $2 \cdot 3$ (SEM 0.04) units in females in the $\mathrm{C}, \mathrm{ON}$ and UN groups, respectively).

Offspring glucose handling at 6 months of age. Maternal prenatal diet influenced baseline fasting glucose before metabolic challenge at 6 months of age (Table 5), with post boc tests revealing higher concentrations in offspring from $\mathrm{ON}$ dams relative to controls $(P<0 \cdot 05)$. In contrast, fasting insulin, NEFA and fasting insulin:glucose were unaffected by prenatal diet. Intravenous administration of glucose induced a significant rise in plasma glucose followed immediately by a rise in insulin (Fig. 3). NEFA concentrations, an index of fat metabolism, began to fall $10 \mathrm{~min}$ after glucose administration (profile not shown). Glucose tolerance (area under the glucose response curve; glucose AUC) was influenced by prenatal diet and post hoc analyses revealed that it was higher $(P<0.05)$ in offspring from $\mathrm{ON}$ dams relative to controls (Table 5), reflecting a reduced rate of glucose clearance from 45 to $120 \mathrm{~min}$ after the glucose bolus in the former group (Fig. 3(a)). By contrast, insulin sensitivity (area under the insulin response curve; insulin AUC), NEFA AUC, and insulin AUC:glucose AUC (an index of relative insulin secretion) were not influenced by prenatal diet (Table 5 and Fig. 3(b)). No sex-specific effects were evident. Irrespective of prenatal diet and sex, both birth weight and FGR from birth to 6 months of age were correlated with fasting glucose concentrations in contrasting directions (Fig. 4). Similar but less strong associations were evident between both birth weight and FGR, and the glucose AUC $(r-0.281, P<0.04$ and $r 0.254, P<0.06$, respectively). No such relationships were evident between current weight and adiposity at the time of metabolic challenge and fasting glucose concentrations or glucose AUC ( $P>0 \cdot 3$, data not shown).

Offspring growth rates and adiposity following postnatal dietary modification. As per the study design, mean birth weight, FGR, live weight and external adiposity at the point of allocation to the postnatal dietary modification groups were equivalent within sex (Table 4). Furthermore, the three contrasting prenatal maternal dietary intakes were equally represented within the ADLIB $v$. NORM female offspring groups (four, three and five offspring from $\mathrm{C}$, ON and UN dams, respectively, per group). In the male ADLIB group there was four, five and five offspring, and in the NORM group four, five and six offspring from $\mathrm{C}, \mathrm{ON}$ and UN dams, respectively. After the application of the contrasting postnatal dietary treatments, weight, adiposity and FGR diverged in both sexes and were statistically different by 10 months of age (i.e. approximately $90 \mathrm{~d}$ after the start of dietary modification; data not shown). FGR between 7 and 12 months of age, and weight and adiposity at 12 months of age were higher in the ADLIB than in the NORM group (Table $4 ; P<0 \cdot 001$ ). Although males remained heavier than females within both postnatal diet groups, this was not statistically different at 12 months of age.

Offspring glucose handling at 12 months of age. Following a 5-month period of postnatal dietary modification baseline fasting glucose, insulin and NEFA concentrations after an overnight fast were higher in ADLIB compared with NORM groups of both sexes (Table 6). Similarly the insulin AUC and NEFA AUC and the insulin:glucose AUC were elevated in ADLIB males and females. Glucose AUC was influenced by both sex and postnatal diet and was greatest in ADLIB-fed females. With the exception of fasting glucose concentrations, prenatal diet had no long-term impact on any of the metabolic parameters measured and thus data are not shown. Table 7 details the former in relation to all main effects evaluated, namely prenatal diet, sex and postnatal diet. Female offspring from prenatally ON dams who were subsequently fed ADLIB had significantly higher fasting glucose concentrations than all other groups except the ADLIB males from $\mathrm{C}$ dams.

Correlation coefficients were calculated to check for relationships between offspring size and growth (i.e. birth weight, FGR and weight and adiposity at 12 months of age) and the main metabolic parameters measured before and 
after glucose challenge (glucose, insulin) according to postnatal dietary treatment group and sex. Current weight and adiposity at 12 months of age were both positively associated with fasting insulin concentrations, and with insulin AUC in NORM males ( $n$ 15) and females ( $n$ 12), ( $r 0.706$ to 0.817 , minimum $P$ value $<0 \cdot 01)$. A similar relationship between weight and adiposity, and insulin AUC was only evident in ADLIB-fed males ( $n$ 14) and females ( $n$ 12), ( $r$ 0.641 to 0.709 , minimum $P$ value $<0.025$ ). By contrast, neither current weight nor adiposity was associated with fasting or AUC glucose concentrations $(P>0 \cdot 3)$. A negative relationship between birth weight and both fasting glucose and glucose AUC was evident in ADLIB females only $(r-0.632, P<0.028$ and $r-0.604, P<0.038$, respectively). The former relationship is shown in Fig. 5 for ADLIB compared with NORM female offspring. No such relationship was evident for males in either
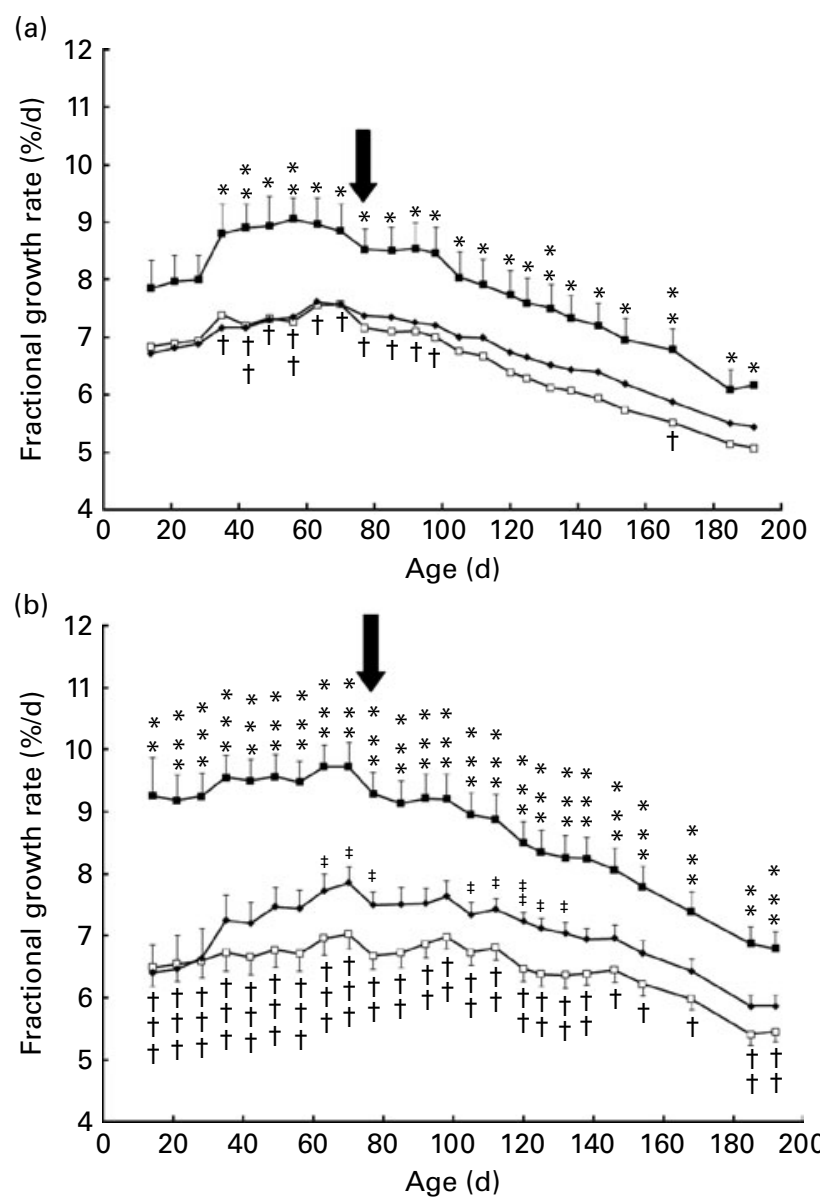

Fig. 2. Weekly changes in fractional growth rate during the first 6 months of life in female (a) and male (b) offspring born to optimally nourished control $(\square)$, overnourished $(\boldsymbol{\square})$ and undernourished $(\bullet)$ adolescent dams (for a detailed description of the dietary manipulations during pregnancy, see Materials and methods). After parturition all ewes were fed a complete diet ad libitum. Lambs were weaned from their mothers at 11 weeks of age $(\downarrow)$ and similarly had ad libitum access to the same complete diet thereafter. Values are means, with standard errors represented by vertical bars. Mean values significantly different between control and overnourished groups: ${ }^{*} P<0.05, \quad{ }^{* *} P<0.01, \quad{ }^{\star \star \star} P<0.001$. Mean values significantly different between overnourished and undernourished groups: $\dagger P<0.05$, $\dagger^{\dagger} P<0.01$, t†† $P<0.001$. Mean values significantly different between control and undernourished groups: $\ddagger P<0.05$, 㧊 $P<0.01$. 


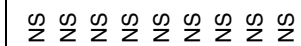

$a$

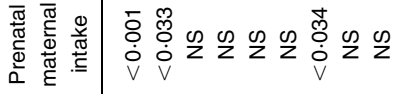

违

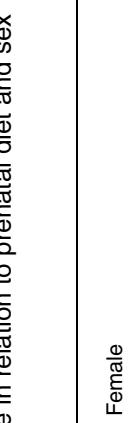

$\left|\begin{array}{l} \\ \frac{0}{o} \\ 5 \\ z \\ s\end{array}\right|$

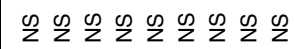

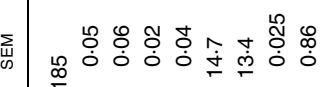

裉

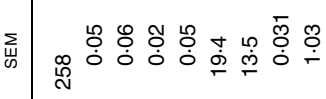

$\mid \begin{aligned} & \widehat{0} \\ & \vdots \\ & z \\ & \vdots\end{aligned}$

䍃

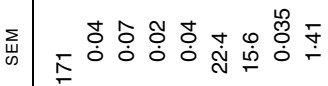

$\stackrel{\substack{\infty \\ \subseteq}}{0}$

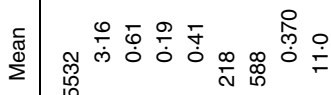

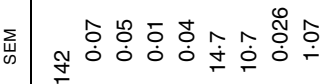

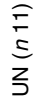

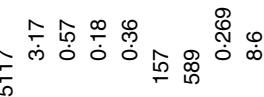

端

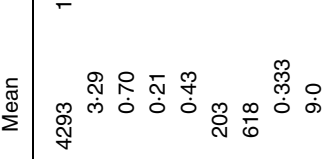

謧

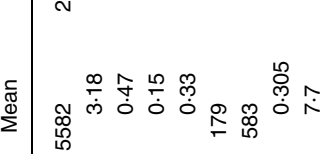

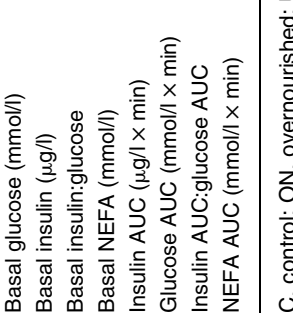

postnatal diet group $(P>0 \cdot 3)$. There was no relationship between FGR from 7 to 12 months of age and glucose responses at 12 months of age in either sex, but FGR during the first 6 months of postnatal life was positively correlated with fasting glucose and glucose AUC at 12 months in ADLIB females $(r 0.720, P<0.008$ and $r 0.586, P<0.045)$.

\section{Discussion}

\section{Pregnancy outcome and initial offspring growth}

Independent studies have previously shown that pregnancy outcome in young adolescent sheep is sensitive to variations in gestational intake at both ends of the nutritional spectrum.

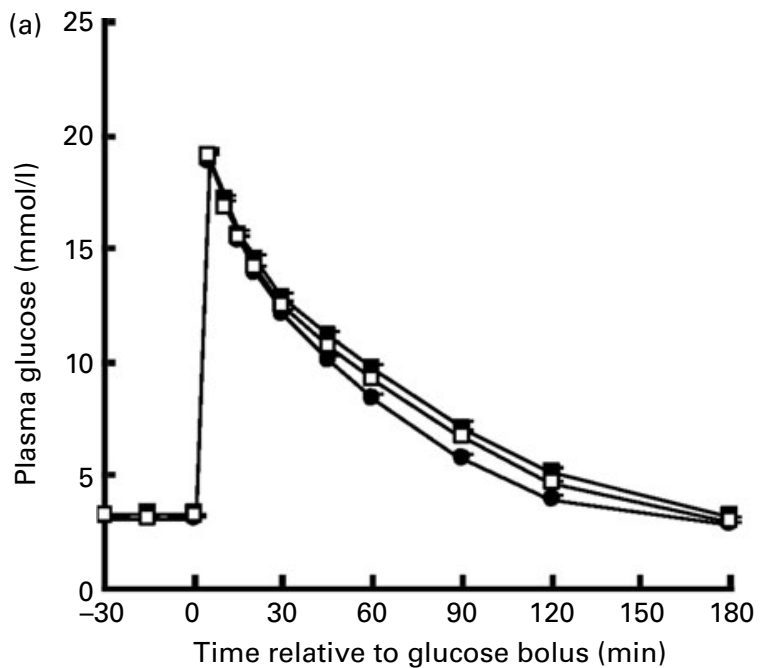

(b)

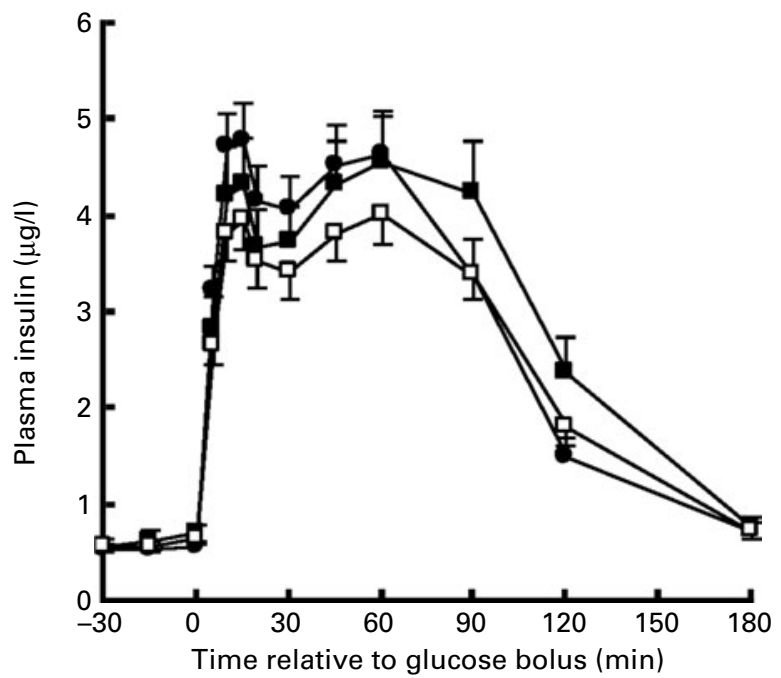

Fig. 3. Plasma glucose (a) and insulin (b) concentrations following bolus administration of glucose $(0.5 \mathrm{~g} / \mathrm{kg}$ body weight; time 0$)$ in offspring born to optimally nourished control $(\square)$, overnourished $(\square)$ and undernourished $(\bullet)$ adolescent dams and studied at 6 months of age (for a detailed description of the dietary manipulation of mothers during pregnancy and offspring diet during the first 6 months of life, see Materials and methods). Values are means, with standard errors represented by vertical bars. For glucose clearance, individual pairwise comparisons revealed $P<0.05$ for offspring from control $v$. overnourished groups at 45, 60, 90 and $120 \mathrm{~min}$, and for offspring from control $v$. undernourished groups at 60,90 and $120 \mathrm{~min}$ after glucose. 

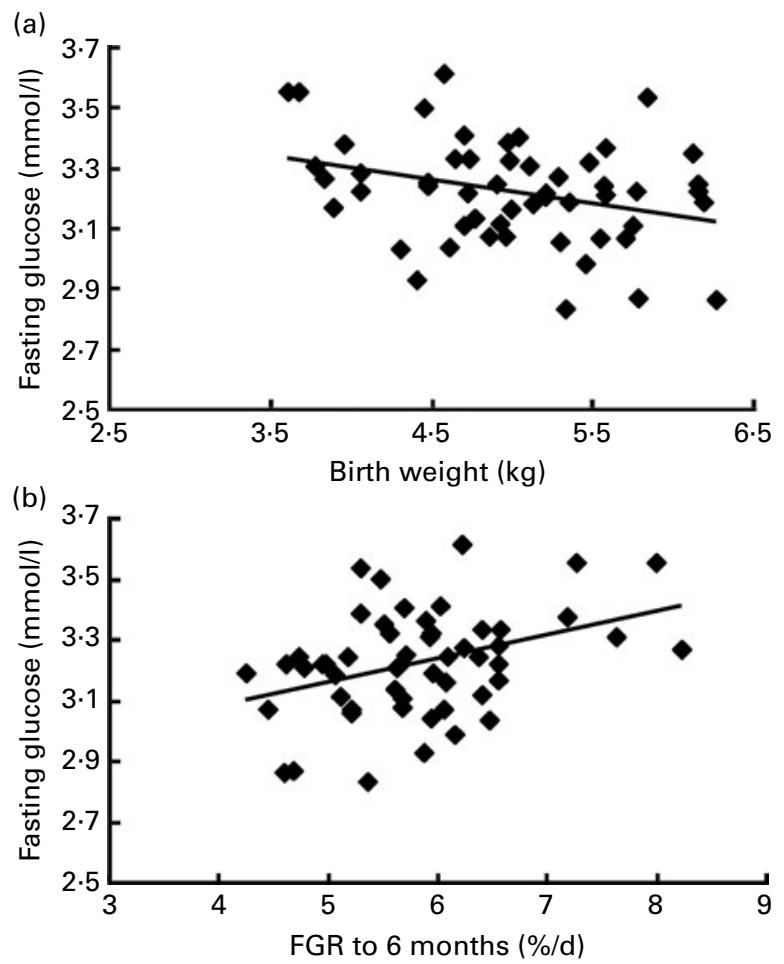

Fig. 4. Relationship between mean fasting plasma glucose concentrations at 6 months of age and (a) birth weight $\left(R^{2} 0.0998 ; P<0.021\right)$ and (b) fractional growth rate (FGR) from birth to 6 months of age $\left(R^{2} 0.1451 ; P<0.005\right)$ for all offspring ( $n 53)$ irrespective of prenatal diet and sex.

In the present study dams with equivalent weight and adiposity at conception and exposed to both nutritional extremes from the end of the first week of pregnancy have been examined relative to optimally nourished controls in a single highly controlled experiment which confirms that lamb birth weight was $\mathrm{C}>\mathrm{UN}>\mathrm{ON}$ groups. The reduction in birth weight in the ON group was associated with reduced fetal placental mass and is commensurate with prior observations of reduced vascular development, uteroplacental blood flows, nutrient uptakes and total placentome weight in late pregnancy in similar animals ${ }^{(16,38)}$. Counterintuitively, ON pregnancies were characterised in the present study by a higher birth weight:placental weight ratio, suggesting relative upregulation of placental nutrient transfer efficiency; however, in spite of this presumed adaptation, the degree of placental growth restriction was such that fetal body growth was still constrained. By contrast, the modest but statistically significant reduction in birth weight achieved in UN adolescents was independent of fetal placental mass, and birth weight: placental weight ratio was equivalent to the optimally nourished controls. This extends previous observations in late gestation $^{(22)}$ and confirms that low maternal nutrient supply is the primary limitation to fetal growth in these pregnancies. In the present study, pregnancies progressed to term and gestation length was equivalent in $\mathrm{C}$ and $\mathrm{UN}$ dams and was more than $4 \mathrm{~d}$ longer than in the ON group. Premature delivery is a consistent feature of the ON model and gestation length is shortest in the pregnancies with the smallest placentae ${ }^{(39)}$. While precise mechanisms have not been proven, nutritionally

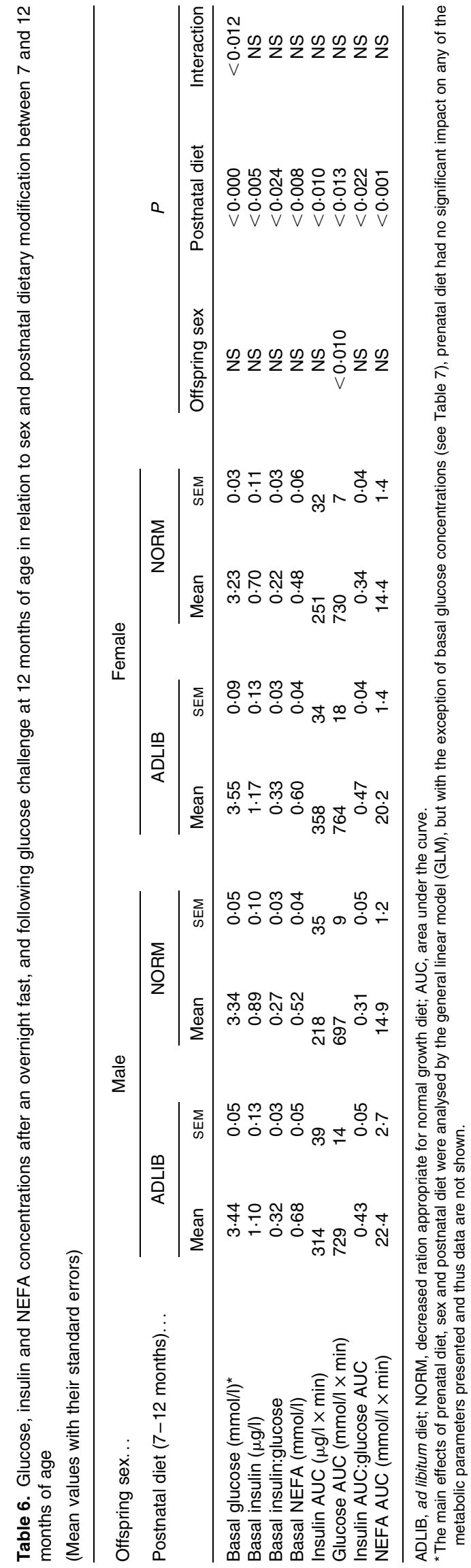


Table 7. Fasting glucose concentrations at 12 months of age in relation to prenatal diet, sex and postnatal dietary modification between 7 and 12 months of age

(Mean values with their standard errors of three samples measured in duplicate per animal)

\begin{tabular}{|c|c|c|c|c|c|}
\hline \multirow[b]{2}{*}{ Maternal prenatal diet } & \multirow[b]{2}{*}{ Sex } & \multirow[b]{2}{*}{ Postnatal diet } & \multirow[b]{2}{*}{$n$} & \multicolumn{2}{|c|}{$\begin{array}{l}\text { Fasting glucose } \\
\qquad(\mathrm{mmol} / \mathrm{l})^{*}\end{array}$} \\
\hline & & & & Mean & SEM \\
\hline Control & Male & ADLIB & 4 & $3 \cdot 62^{a, b}$ & 0.105 \\
\hline Control & Male & NORM & 4 & $3.39^{b}$ & 0.087 \\
\hline Control & Female & ADLIB & 4 & $3.35^{\mathrm{b}}$ & 0.016 \\
\hline Control & Female & NORM & 4 & $3 \cdot 32^{b}$ & 0.043 \\
\hline Overnourished & Male & ADLIB & 5 & $3.50^{\mathrm{b}}$ & 0.036 \\
\hline Overnourished & Male & NORM & 5 & $3 \cdot 36^{\mathrm{b}}$ & 0.098 \\
\hline Overnourished & Female & ADLIB & 3 & $3.96^{a, c}$ & 0.097 \\
\hline Overnourished & Female & NORM & 3 & $3 \cdot 23^{b}$ & 0.036 \\
\hline Undernourished & Male & ADLIB & 5 & $3 \cdot 26^{b}$ & 0.008 \\
\hline Undernourished & Male & NORM & 6 & $3 \cdot 28^{\mathrm{b}}$ & 0.077 \\
\hline Undernourished & Female & ADLIB & 5 & $3.47^{b}$ & 0.122 \\
\hline Undernourished & Female & NORM & 5 & $3 \cdot 18^{b, d}$ & 0.031 \\
\hline
\end{tabular}

ADLIB, ad libitum diet; NORM, decreased ration appropriate for normal growth diet.

$\mathrm{a}, \mathrm{b}, \mathrm{c}, \mathrm{d}$ Mean values with unlike superscript letters were significantly different $(P<0.05$; Tukey's pairwise comparisons).

${ }^{*}$ Effects: prenatal diet, $P<0.001$; sex, NS; postnatal diet, $P<0.001$; prenatal diet $\times$ sex, $P<0.019$; prenatal diet $\times$ postnatal diet, $P<0.014$; sex $\times$ postnatal diet, $P<0.012$; prenatal diet $\times$ sex $\times$ postnatal diet, $P<0.005$.

mediated suppression of placental steroid secretion is likely to be involved, as both progesterone and oestrogen concentrations are low in these ON animals during the final third of gestation and are individually correlated with gestation length ${ }^{(14,40)}$, whereas progesterone concentrations remain high in UN dams and are similar to those in controls ${ }^{(22)}$.

In the present study gestational intake also influenced nutrient partitioning to the mammary gland, as the quantity of colostrum produced immediately after birth and its total IgG, protein, lactose and energy content were $\mathrm{C}>\mathrm{UN}>\mathrm{ON}$. The design of the study aimed to maximise neonatal survival by ensuring that all lambs received adequate colostrum and milk throughout the first $72 \mathrm{~h}$ of life. Although more lambs in the ON group required colostrum supplementation at birth there was no evidence of impaired lactogenesis persisting in the neonatal period. FGR to 6 months of age were negatively associated with birth weight in both sexes and, although residual effects of prenatal diet and maternal nutrient stores at parturition on lactation performance cannot be dismissed, FGR were highest in the low-birth-weight offspring from ON dams. This rapid catch-up growth, once released from the constraining effect of a poor placental environment, is similar to that observed in other animal models involving placental restriction of fetal growth $^{(29,41)}$ and in studies of intra-uterine growth-restricted human subjects ${ }^{(25,42-44)}$. Intriguingly, relative to controls the low-birth-weight offspring of ON dams had higher total and LDL-cholesterol at birth and during the 11-week suckling period; this may in part reflect the higher body weight-specific perirenal and carcass fat mass previously observed in these small fetuses during late pregnancy ${ }^{(19)}$. Alternatively, the neonatal lipid profile may in part reflect maternal adiposity and presumed enhanced inflammatory status at parturition in ON dams, as observed in infants of diabetic mothers ${ }^{(45,46)}$ and in animal models of maternal hypercholesterolaemia ${ }^{(47)}$. Nonetheless, by 6 months of age the fasting lipid profile was equivalent between groups and fat metabolism (basal and
NEFA responses to glucose) was similarly unaffected by prenatal diet. Body composition was not directly measured in the present study, but serial assessment using dual-energy X-ray absorptiometry in similar groups of low-birth-weight offspring from ON dams revealed increased body fat and reduced bone mineral density at weaning following rapid neonatal catch-up growth, and at 2 years of age, but not at intervening time points co-incident with the maximum lean tissue growth phase associated with adolescence and young adulthood (JM Wallace, RP Aitken and CL Adam, unpublished results). By contrast in the present study there was little evidence of catch-up growth in offspring of UN dams, in keeping with the relatively modest degree of prenatal growth restriction achieved and their normal gestation length.

\section{Glucose handling at 6 months of age}

The main aim of the present study was to examine glucose metabolism in offspring whose prenatal growth trajectories

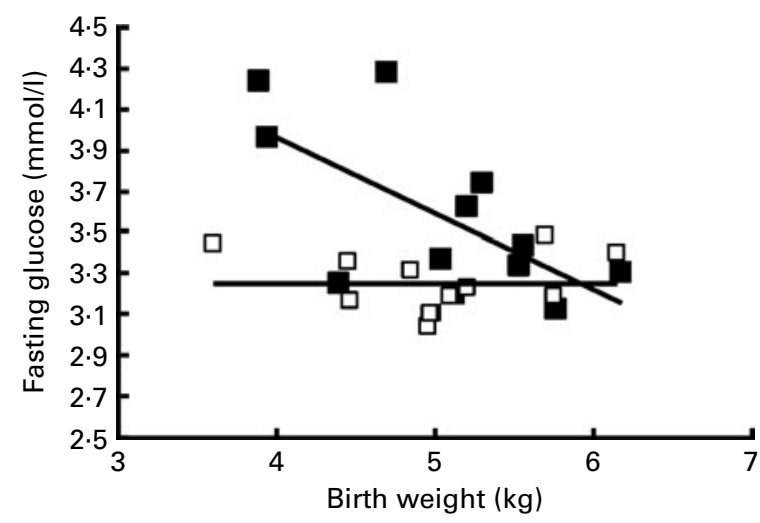

Fig. 5. Relationship between birth weight and mean fasting glucose concentrations at 12 months of age in female offspring with either normal ( $\square$; $R^{2} 0.025$; NS) or ad libitum $\left(\mathbf{\square} ; R^{2} 0.399 ; P<0.028\right)$ access to a complete diet between 7 and 12 months of age ( $n 12$ per group). 
had been impaired by contrasting maternal dietary intake levels during pregnancy. Accordingly we have demonstrated early signs of mild glucose intolerance with increased fasting plasma glucose and increased glucose AUC at 6 months of age in offspring whose prenatal placental and fetal growth trajectories were impaired by maternal overfeeding (22\% decrease in birth weight) relative to normally growing controls. This modest increase in fasting glucose is still within the normal range but is of similar magnitude to that observed in a study of young men with a $29 \%$ differential in birth weight relative to the control population ${ }^{(48)}$ and to that observed at 12 months of age in within-litter comparisons of low- $v$. high-birth-weight piglets ${ }^{(30)}$. By contrast, the more modest degree of prenatal growth restriction achieved by progressive depletion of maternal nutrient reserves throughout pregnancy in UN dams (10\% decrease in birth weight) did not influence glucose metabolism directly. This latter observation is perhaps surprising in view of previously reported associations between maternal undernutrition before and during pregnancy and glucose tolerance (outlined in the Introduction), all of which were independent of birth weight. Nevertheless in the present study, birth weight was negatively associated with both fasting glucose and glucose AUC across the birth weight range achieved by the three dietary manipulations applied. This relationship in offspring whose genetic background was highly controlled by using assisted conception procedures confirms a previous suggestion that achieved weight at birth as an integrated measure of fetal nutrient supply may be more important than maternal nutritional group assignment in determining subsequent postnatal phenotype ${ }^{(49)}$.

The mild but statistically significant glucose intolerance observed in the low-birth-weight offspring from ON dams was independent of any change in insulin sensitivity or relative secretion since fasting insulin, insulin:glucose, insulin AUC and the initial phase of insulin secretion were equivalent between groups. This argues against a programmed pancreatic $\beta$-cell defect as proposed in other ovine studies ${ }^{(10-12)}$ but suggests that these offspring may have altered hepatic glucose production or tissue glucose uptake.

\section{Glucose handling following postnatal dietary modification}

The secondary aim of the present study was to determine whether the relationship between size at birth and glucose intolerance in offspring with ad libitum access to a nutrientdense diet up to 6 months of age could be modulated by a 5-month period of relative nutrient restriction between adolescent and young adult life. Accordingly ADLIB compared with NORM groups of both sexes were compared and, as expected, offspring continuously exposed to the diet ad libitum throughout postnatal life grew faster and were heavier, fatter, and more glucose intolerant and insulin insensitive at 12 months of age. Moreover, although numbers were small, the low-birth-weight female offspring from prenatally ON dams who were fed ad libitum throughout postnatal life had statistically higher fasting glucose concentrations than all but one of the other eleven prenatal diet/postnatal diet/sex group comparisons (Table 7), suggesting that the adverse phenotype persists in a sex-specific manner into early adult life. In addition, the negative relationship between birth weight and glucose intolerance irrespective of prenatal dietary intake group persisted in ADLIB females but was abolished in the NORM females, further suggesting that slowing nutrient intake during the adolescent to young adult period had a beneficial effect on glucose metabolism. Similar relationships were evident between early postnatal FGR and indices of glucose intolerance, suggesting that both intra-uterine and postnatal growth patterns affect glucose production in later life. This is the first observation of a reversal in phenotype in a large animal model but previous studies in rodents have demonstrated proof of concept ${ }^{(33)}$ while other ovine studies indicate that an adverse prenatally programmed phenotype may not become apparent until offspring are exposed to nutritional excess later in adult life ${ }^{(50)}$. Together, these animal studies suggest that appropriate weight control during key phases of postnatal life in human populations could partly ameliorate the well-established negative effects of poor nutrient supply in utero.

Both the persistence of mild glucose intolerance into early adulthood and its reversal by postnatal dietary modification were specific to females. Sex-specific metabolic programming effects have been widely reported previously but are inconsistent. Thus, while in some ovine studies and postnatal ages the effects predominate in females ${ }^{(11)}$, others indicate that male offspring are more sensitive to a variety of environmental effects including prenatal exposure to glucocorticoids ${ }^{(51)}$, methyl-deficient diets ${ }^{(52)}$, maternal undernutrition ${ }^{(50)}$ and placental limitation of fetal nutrient supply ${ }^{(29)}$. However, direct comparison across studies, between sexes and with human cohorts, is confounded by the widespread use of castration in animal models, in contrast to the present study where males remained gonad intact.

In summary, maternal gestational intake at both ends of the nutritional spectrum decreased offspring birth weight but by contrasting mechanisms. Offspring from overnourished dams were most perturbed, being premature and of lowest birth weight, and they exhibited rapid catch-up growth and had mildly impaired glucose tolerance at 6 months of age. Irrespective of maternal prenatal diet, offspring birth weight and the associated postnatal growth pattern predicted glucose intolerance at 6 months of age in both sexes. This negative relationship persisted in female offspring continuously exposed to energy excess through to young adulthood but was abolished by modestly restricting food intake. The present study has implications for weight control following prenatal growth restriction in human populations.

\section{Acknowledgements}

The present study was funded by the Scottish Government (Workpackage 4.2: Dietary Strategies for the Obesogenic Environment). Graham Horgan (BioSS) provided statistical advice.

J. M. W. designed the study, J. M. W., J. S. M. and R. P. A. carried out the animal and laboratory procedures, J. M. W. 
analysed the data and J. M. W. wrote the manuscript with input from C. L. A.

None of the authors had any financial or personal conflicts of interest.

\section{References}

1. Barker DJ, Gluckman PD, Godfrey KM, et al. (1993) Fetal nutrition and cardiovascular disease in adult life. Lancet 341, 938-941.

2. Hales CN, Barker DJ, Clark PM, et al. (1991) Fetal and infant growth and impaired glucose tolerance at age 64. BMJ 303, 1019-1022.

3. Whincup PH, Kaye SJ, Owen CJ, et al. (2008) Birth weight and risk of type 2 diabetes. A systematic review. JAMA 300, 2886-2897.

4. Ravelli ACJ, van der Meulen JHP, Michels RPJ, et al. (1998) Glucose tolerance in adults after prenatal exposure to famine. Lancet 351, 173-177.

5. Ravelli ACJ, van der Meulen JHP, Osmond C, et al. (1999) Obesity at the age of $50 \mathrm{y}$ in men and women exposed to famine prenatally. Am J Clin Nutr 70, 811-816.

6. Roseboom TJ, van der Meulen JHP, Osmond C, et al. (2000) Plasma lipid profiles in adults after prenatal exposure to the Dutch famine. Am J Clin Nutr 72, 1101-1106.

7. Roseboom TJ, van der Meulen JHP, Osmond C, et al. (2000) Coronary heart disease after prenatal exposure to the Dutch famine, 1944-45. Heart 84, 595-598.

8. Luther JS, Redmer DA, Reynolds, et al. (2005) Nutritional paradigms of ovine fetal growth restriction: implications for human pregnancy. Hum Fert 8, 179-187.

9. McMillen IC \& Robinson JS (2005) Developmental origins of the metabolic syndrome: prediction, plasticity, and programming. Physiol Rev 85, 571-633.

10. Cripps RL, Green LR, Thompson J, et al. (2008) The effect of maternal body condition score before and during pregnancy on the glucose tolerance of adult sheep offspring. Reprod Sci 15, 448-456.

11. Todd SE, Oliver MH, Jaquiery AL, et al. (2009) Periconceptional undernutrition of ewes impairs glucose tolerance in their adult offspring. Pediat Res 65, 409-413.

12. Ford SP, Hess BW, Schwope MM, et al. (2007) Maternal undernutrition during early to mid-gestation in the ewe results in altered growth, adiposity, and glucose tolerance in male offspring. J Anim Sci 85, 1285-1294.

13. Gardner DS, Tingey K, Van Bon BWM, et al. (2005) Programming of glucose-insulin metabolism in adult sheep after maternal undernutrition. Am J Physiol Reg Integr Comp Phys 289, R947-R954.

14. Wallace JM (2011) Adaptive maternal, placental and fetal responses to nutritional extremes in the pregnant adolescent: lessons from sheep. In Reproduction and Adaptation, pp. 112-127 [L Rosetta and R Goto, editors]. Cambridge: Cambridge University Press. (In the Press).

15. Wallace JM, Regnault TRH, Limesand SW, et al. (2005) Investigating the causes of low birth weight in contrasting ovine paradigms. J Physiol 565, 19-26.

16. Wallace JM, Bourke DA, Aitken RP, et al. (2002) Blood flows and nutrient uptakes in growth-restricted pregnancies induced by overnourishing adolescent sheep. Am J Physiol Reg Integ Comp Physiol 282, R1027-R1036.

17. Wallace JM, Bourke DA, Aitken RP, et al. (2002) Placental glucose transport in growth-restricted pregnancies induced by overnourishing adolescent sheep. J Physiol 547, 85-94.
18. Wallace JM, Bourke DA, Aitken RP, et al. (2000) Relationship between nutritionally-mediated placental growth restriction and fetal growth, body composition and endocrine status during late gestation in adolescent sheep. Placenta 21, 100-108.

19. Matsuzaki M, Milne JS, Aitken RP, et al. (2006) Overnourishing pregnant adolescent ewes preserves perirenal fat deposition in their growth-restricted foetuses. Reprod Fertil Dev 18, 357-364.

20. Wallace JM, Milne JS, Aitken RP, et al. (2007) Sensitivity to metabolic signals in late gestation growth restricted fetuses from rapidly growing adolescent sheep. Am J Physiol Endocrinol Metab 293, E1233-E1241.

21. Luther JS, Aitken RP, Milne JS, et al. (2007) Maternal and fetal growth, body composition, endocrinology and metabolic status in undernourished adolescent sheep. Biol Reprod 77, 343-350

22. Luther JS, Aitken RP, Milne JS, et al. (2007) Placental growth, angiogenic gene expression and vascular development in undernourished adolescent sheep. Biol Reprod 77, 351-357.

23. Huxley RR, Shiell AW \& Law CM (2000) The role of the size at birth and postnatal catch-up growth in determining systolic blood pressure: a systematic review of the literature. J Hypertens 18, 815-831.

24. Mericq V, Ong KK, Bazaes R, et al. (2005) Longitudinal changes in insulin sensitivity and secretion from birth to age three years in small- and appropriate-for-gestationalage children. Diabetologica 48, 2609-2614.

25. Ong KK, Ahmed ML, Emmett PM, et al. (2000) Association between postnatal catch-up growth and obesity in childhood: prospective cohort study. BMJ 320, 967-971.

26. Ong KK, Petry CJ, Emmett PM, et al. (2004) Insulin sensitivity and secretion in normal children related to size at birth, postnatal growth, and plasma insulin-like growth factor-I levels. Diabetologica 47, 1064-1070.

27. Bieswal F, Ahn MT, Reusens B, et al. (2006) The importance of catch-up growth after early malnutrition for the programming of obesity in the male rat. Obesity 14, 1330-1343.

28. Jimenez-Chillaron JC, Hernandez-Valencia M, Reamer C, et al. (2005) $\beta$-Cell secretory dysfunction in the pathogenesis of low birth weight-associated diabetes. A murine model. Diabetes 54, 702-711.

29. Owens JA, Thavaneswaran P, De Blasio MJ, et al. (2007) Sexspecific effects of placental restriction on components of the metabolic syndrome in young adult sheep. Am J Physiol Endocrinol Metab 292, E1879-E1889.

30. Poore KR \& Fowden AL (2002) The effect of birth weight on glucose tolerance in pigs at 3 and 12 months of age. Diabetologica 45, 1247-1254.

31. Poore KR \& Fowden AL (2004) Insulin sensitivity in juvenile and adult Large White pigs of low and high birthweight. Diabetologica $\mathbf{4 7}, 340-348$.

32. Coupé B, Grit A, Darmaun D, et al. (2009) The timing of 'catch-up growth' affects metabolism and appetite regulation in male rats born with intrauterine growth restriction. $A m J$ Physiol Regul Integr Comp Physiol 297, R813-R824.

33. Jimenez-Chillaron JC, Hernandez-Valencia M, Lightner A, et al. (2006) Reductions in caloric intake and early postnatal growth prevent glucose intolerance and obesity associated with low birth weight. Diabetologia 49, 1974-1984.

34. Wallace JM, Da Silva P, Aitken RP, et al. (1997) Maternal endocrine status in relation to pregnancy outcome in rapidly growing adolescent sheep. J Endocrinol 155, 359-368.

35. Russel AJF, Doney JM \& Gunn RG (1969) Subjective assessment of body fat in live sheep. J Agric Sci Camb $\mathbf{7 2}$ $451-454$. 
36. Wallace JM, Milne JS, Redmer DA, et al. (2006) Effect of diet composition on pregnancy outcome in overnourished rapidly growing adolescent sheep. Br J Nutr 96, 1060-1068.

37. MacRae JC, Bruce LA, Hovell B, et al. (1991) Influence of protein nutrition on the response of growing lambs to exogenous bovine growth hormone. J Endocrinol 130, 53-61.

38. Redmer DA, Luther JS, Milne JS, et al. (2009) Fetoplacental growth and vascular development in overnourished adolescent sheep at day 50, 90 and 130 of gestation. Reproduction 137, 749-757.

39. Wallace JM, Luther JS, Milne JS, et al. (2006) Nutritional modulation of adolescent pregnancy outcome - a review. Placenta 27, Suppl. A, S61-S68.

40. Wallace JM, Bourke DA, Da Silva P, et al. (2003) Influence of progesterone supplementation during the first third of pregnancy on fetal and placental growth in overnourished adolescent ewes. Reproduction 126, 481-487.

41. De Blasio MJ, Gatford KL, McMillen IC, et al. (2007) Placental restriction of fetal growth increases insulin action, growth and adiposity in the young lamb. Endocrinology 148, $1350-1358$.

42. Albertsson-Wikland K \& Karlberg J (1997) Postnatal growth of children born small for gestational age. Acta Paediatr Suppl 423, 193-195.

43. Hokken-Koelega AC, De Ridder MA, Lemmen RJ, et al (1995) Children born small for gestation age: do they catch up? Pediatr Res 38, 267-271.

44. Tenovuo A, Kero P, Piekkala P, et al. (1987) Growth of 519 small for gestational age infants during the first two years of life. Acta Paediatr Scand 75, 636-646.

45. Lindegaard MLS, Svarrer EMM, Damm P, et al. (2008) Increased LDL cholesterol and CRP in infants of mothers with type 1 diabetes. Diabetes Metab Res Rev 24, 465-471.
46. Merzouk H, Madani S, Korso N, et al. (2000) Maternal and fetal serum lipid and lipoprotein concentrations and compositions in type 1 diabetic pregnancy: relationship with maternal glycemic control. I Lab Clin Med 136, 441-448.

47. Palinski W, D'Armiento FP, Witztum JL, et al. (2001) Maternal hypercholesterolemia and treatment during pregnancy influence the long-term progression of atherosclerosis in offspring of rabbits. Circ Res 89, 991-996.

48. Jensen CB, Storgaard H, Dela F, et al. (2002) Early differential defects in insulin secretion and action in 19 year old Caucasion men who had low birth weight. Diabetes $\mathbf{5 1}$, $1271-1280$

49. Oliver MH, Breier BH, Gluckman PD, et al. (2002) Birth weight rather than maternal nutrition influences glucose tolerance, blood pressure, and IGF-1 levels in sheep. Pediatr Res 52, 516-524.

50. Rhodes P, Craigon J, Gray C, et al. (2009) Adult-onset obesity reveals prenatal programming of glucose-insulin sensitivity in male sheep nutrient restricted during late gestation. PLos One 4, e7393.

51. De Blasio MJ, Dodic M, Jeffries AJ, et al. (2007) Maternal exposure to dexamethasone or cortisol in early pregnancy differentially alters insulin secretion and glucose homeostasis in adult male sheep offspring. Am J Physiol Endocrinol Metab 293, E75-E82.

52. Sinclair KD, Allegrucci C, Singh R, et al. (2007) DNA methylation, insulin resistance, and blood pressure in offspring determined by maternal periconceptional B vitamin and methionine status. PNAS 104, 19351-19356.

53. Wallace JM, Milne JS, Matsuzaki, et al. (2008) Serial measurement of uterine blood flow from mid to late gestation in growth restricted pregnancies induced by overnourishing adolescent sheep dams. Placenta 29, 718-772. 